ARAŞTIRMA / RESEARCH

\title{
Deprem travmasının erken dönem psikolojik etkileri ve olası risk faktörleri
}

Early psychological effects of earthquake trauma and possible risk factors

\author{
Gülay Taşc1 1 (iD, Filiz Özsoy \\ ${ }^{1}$ Elazı̆̆ Fethi Sekin Şehir Hastanesi, Elazığ \\ ${ }^{2}$ Tokat Devlet Hastanesi, Psikiyatri Kliniği, Tokat
}

\begin{abstract}
Purpose: The purpose of the study was to identify the psychiatric symptoms that emerged after the earthquake on 24.01.2020 in Sivrice County of Elazig as the epicenter, where a total of 44 people died and over 1500 people were injured.
\end{abstract}

Materials and Methods: The study was conducted 2.5 months after earthquake. Sociodemographic Data Form, Beck Anxiety Scale (BAS), Beck Depression Scale (BDS), Peritraumatic Dissociation Scale (PTDS), DSM-5 Post Traumatic Stress Disorder Check List (PTSDCL) were applied to all participants.

Results: A total of 360 people were included in the study, 284 of whom were the victims of the earthquake, and 76 constituted the Control Group. The mean age of the

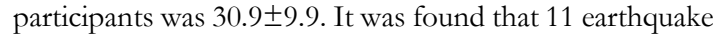
victims $(3.87 \%)$ lost their relatives in the earthquake. The BAS and BDS scores of the participants did not differ between the groups. The calculated scores of earthquake victims were much higher in PTDS and PTSDCL.

Conclusion: Trauma and dissociation scores were increased, and the depression and anxiety levels of the survivors did not increase after the earthquake. Based on our results it is important to identify the psychiatric symptoms of survivors after disasters such as earthquakes, respond to diseases that might be detected quickly, support them psychiatrically-socially in terms of their being able to become used to their loss/new life order and for their psychiatric well-being.

Keywords: Earthquake, psychiatric symptoms, dissociation, post-traumatic stress disorder
Amaç: Bu çalışmanın amacı; 24.01.2020 tarihinde merkez üssü Elazığ Sivrice ilçesi olan, toplamda 44 kişinin vefat ettiği ve 1500 üzerinde insanın yaralandı̆̆ deprem sonrası ortaya çıan psikiyatrik semptomları ortaya koyabilmektir. Gereç ve Yöntem: Çalışma depremden 2,5 ay sonra yapılmıştır. Tüm katılımcılara; sosyodemografik veri formu, Beck Anksiyete Ölçeği (BAÖ), Beck Depresyon Ölçeği (BDÖ), Peritravmatik Disosiyasyon Ölçeği (PTDÖ), DSM-5 Travma Sonrası Stres Bozukluğu Kontrol Listesi (TSSBKL) uyguland.

Bulgular: Çalışmaya 360 kişi; 284 kişi deprem mağduru ve 76 kişi de kontrol grubu olarak alındı. Katılımcıların yaş

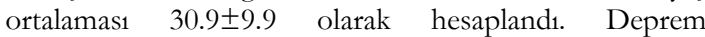
mağdurlarından yakınını kaybeden 11 kişi (\%3.87) olduğu saptandi. Katilımciların BAÖ ve BDÖ skorları gruplar arasında farklılık göstermedi. PTDÖ ve TSSBKL için deprem mağdurlarının hesaplanan skorları çok daha yüksekti.

Sonuç: Çalışmamızda deprem sonrası hayatta kalanların depresyon ve ansiyete düzeyleri artmasa da travma ve dissosiyasyon skorlarının artmış olduğu görüldü. Elde ettiğimiz sonuçlara dayanarak; deprem gibi felaketler sonrası hayatta kalanların psikiyatrik ve sosyal olarak iyi desteklenmeleri, hem kayıplarına alıșabilmeleri hem de psikiyatrik olarak rahatsızlanmamaları açısından önemlidir.

Anahtar kelimeler: Deprem, psikiyatrik semptomlar, dissosiyasyon, travma sonrası stres bozukluğu 


\section{GİRİŞ}

"Deprem”; dünya yüzeyinin sürekli sallanması olarak tanımlanır. Her yıl dünya çapında yarım milyon deprem meydana geldiği tahmin edilmektedir. Ancak bu depremlerin çoğu ya çok küçük oldukları ya da uzak bölgelere vurdukları için tespit edilememektedir ${ }^{1}$. Birçok farklı doğal afet türü içinde depremler, yıkıc1, kontrol edilemez, en fazla göçe yol açan ve yaşamı en çok tehdit edenler olarak kabul edilmektedir ${ }^{2}$. Tarihte kaydedilen en büyük can kayıplarının yaşandığı depremler; 1556 yılında Çin Shaanxi eyaletinde 830 binden fazla insan vefat etmiştir. 1999 y1lında ülkemiz Marmara bölgesinde yaşanan depremde resmi rakamlara göre 17.480 kişi hayatını kaybetmiştir. 2011 yilında Japonya'da yaşanan depremde 15.900 kişinin öldüğü ve 2.531 kişinin ise hâlen kayıp olduğu bildirilmiştir. 2015 yilinda Nepal'de meydana gelen depremde ise 8.000 kişi ölmüştür ${ }^{3}$. Yaşanan depremin boyutuna bağlı olarak felaketler; evsizlik, sevdiklerinin kaybı, önemli akıl ruh sağlığı sorunları ortaya çıkabilmektedir ${ }^{3-6}$.

Deprem gibi büyük felaketlerden sonra; fiziksel engellilik, enfeksiyon hastalıkları ve salgınlar gibi hastaliklar, barınma ve sosyal sorunlar ortaya çıkabilmektedir. Tüm bunlara ek olarak depresif semptomlar, anksiyete semptomları, özellikle travma sonrası stres bozukluğu görülebilmektedir ${ }^{7,8}$. Büyük felaketlerden sonra ortaya çıan psikiyatrik semptomlar ve hastalıklar yaş, cinsiyet, medeni durum, afet sonrası olan can ve mal kayıplarına, eski sağlık sorunlarına ve içinde bulunulan ülkenin ekonomik şartlarına göre değişmektedir. Ek olarak psikiyatrik hastalıklarda erken tanı konulması ve müdahale edilmesi de hastalığın seyrini değiştirebilmektedir? 9

Can ve mal kaybına yol açan deprem gibi felaketler sonrasi hayatta kalanlarda; evlerinin durumu ve toplanma yerleri ile ilgili belirsizlik, yakınlarını, evlerini, işlerini, sosyal yaşam alanlarını kaybetme ya da kaybetme korkusu ile birlikte ruhsal olarak zorlu bir süreç başlamaktadır ${ }^{6}$. Literatürde yapılan çalışmalarda deprem mağduru insanlarda yaygin anksiyete bozukluğu (YAB), majör depresif bozukluk (MDB), akut stres bozukluğu (ASB) gibi psikiyatrik hastalık oranlarının arttığ1 tespit edilmiştir ${ }^{8}$. Üzerinde en fazla çalışma yapılan ise; ASB ve travma sonrası stres bozukluğu (TSSB) olmuştur ${ }^{3-6,7}$. Daha az sayıda çalışmada uyku bozuklukları ve somatik semptomlar oluşabileceği bildirilmiştir ${ }^{8}$. $\mathrm{Bu}$ bilgilerden yola çıkarak biz çalışmamızda; 24.01.2020 tarihinde merkez üssü Elazığ'ın Sivrice ilçesi olan, toplamda 44 kişinin vefat ettiği ve 1500 üzerinde insanın yaralandığ1 depremin ortaya çıkardığ1 psikiyatrik semptomlar ve hastalıkları ortaya koyabilmek amaçlanmıştır. Hayatta kalan kişilerin; travma semptomları, anksiyete, depresyon ve disosiyasyon düzeylerini bir arada değerlendirip psikiyatrik olarak semptomları erken far edip, tanı koyabilmek hedeflenmiştir.

\section{GEREÇ VE YÖNTEM}

Çalışmanın yapılabilmesi için Fırat Üniversitesi Tıp Fakültesi Klinik Araştırmalar Yerel Etik Kurulundan 13.04.2020 tarih ve 2020/06-26 say1 numarası ile onay alındı. Çalışma Helsinki Deklarasyonu'na ${ }^{10}$ uygun şekilde yürütüldü. Çalışma 24.01.2020 tarihinde merkez üssü Elazığ Sivrice ilçesi olan, Kandilli Rasathanesi tarafindan büyüklüğü 6.8 olarak bildirilen deprem sonrası planlanmıştır. Çalışma gözlemsel; kesitsel niteliktedir ve örneklem rastgele seçilmiştir. Çalışmaya alınma kriterleri; Elazığ'da depremi yaşayan, mevcut hali ile psikiyatrik olarak DSM-5 tanı kriterlerini karşılayacak hastalığı olmayan ve katılmaya gönüllü, okuma yazması olan, 18-55 yaş arası kişiler olarak belirlenmiştir. Yaş aralığı belirlenirken; yapılan görüşmelerde kişilerin verilen formları doldurabilme ve tamamlayabilme durumları göz önüne alınmıștır. Medikal tedavi almasını gerektirir kronik hastalıkları olan, psikiyatrik tedavi alımı olduğunu bildiren katılımcılar ile çalışmaya katılmak istemeyen kişiler çalışma dışı bırakılmıştır. Son olarak alkol/madde kullanım bozukluğu olan kişiler de çalışmaya dahil edilmemiştir.

Sağlıklı kontrol grubu ruh sağlığı ve hastalıkları polikliniğine iş başvurusu için "psikiyatrik olarak sağlam" raporu almak için gelen kişilerden gönüllü olanlar arasından seçilmiştir. Olgu grubu ile demografik veriler açısından eşleşen, hayatının herhangi bir döneminde deprem yaşamamış ve mevcut hali ile psikiyatrik tedavi alımı olmayan kişiler kontrol grubu olarak çalışmaya alındı.

\section{Uygulama}

Katılımcilara; sosyodemografik veri formu, Beck Anksiyete Ölçeği (BAÖ), Beck Depresyon Ölçeği (BDÖ), Peritravmatik Dissosiyasyon Ölçeği (PTDÖ); DSM-5 Travma Sonrası Stres Bozukluğu Kontrol Listesi (TSSBKL) uyguland. Tüm katılımcılardan aydınlatılmış onam formu alındı. Çalışma 15.04.2020-15.06.2020 tarihleri arasında 
yapılmıştır. Belirtilen tarihler arasında deprem çadırlarında depremi yaşayan kişiler ile yapılan psikiyatrik görüşmelerde çalışmaya dahil edilme ölçütlerini karşılayanlara formlar görüşme esnasında yapılmıştır. Sosyodemografik veri formu araştırmacılar tarafından uygulanırken diğer formları görüşme sonrası kişiler kendisi doldurmuştur.

\section{Veri toplama araçları}

\section{Sosyodemografik veri formu}

Literatür taranması ve çalışmanın amaçları göz önüne alınarak araştırmacılar tarafindan hazırlanmıştır. Yaş, cinsiyet, medeni durum, eğitim seviyesi, meslek gibi demografik veriler ve tedavi almasını gerektirir tıbbi ve/veya psikiyatrik hastalığı olup olmadığı gibi klinik değerlendirme sorularını içermektedir. Bunlara ek olarak depremi Elazığ il merkezinde yaşayan olgu grubuna depremi nerede yaşadığı, deprem sarsıntısını hissedip hissetmediği, deprem sonrası evinde hasar olup olmadığı, deprem sonrası şehir değiştirip değiştirmediği, deprem sırasında hissettiği korku düzeyini ve yeniden deprem olabileceği ile ilgili hissettiği korkuyu değerlendiren sorulardan oluşmuştur.

\section{Beck Anksiyete Ölçeği (BAÖ)}

Kişinin yaşadığ 1 anksiyete belirtilerinin şiddetini ve sıklığını ölçmek amacıyla kullanılır. Toplamda 21 sorudan oluşan ve her maddesi 0-3 arasinda puanlanan bir öz bildirim ölçeğidir. Hesaplanan puanın yüksekliği yaşanan anksiyetenin yüksekliğini göstermektedir ${ }^{11,12}$.

\section{Beck Depresyon Ölçeği (BDÖ)}

Kişinin yaşadığı depresif belirtilerin şiddetini ve sıklığını belirlemek amacı ile kullanılır. Toplamda 21 sorulu, her maddesi 0-3 arasinda puanlanan bir öz bildirim ölçeğidir ${ }^{13,14}$.

\section{Peritravmatik Dissosiyasyon Ölçeği (PTDÖ)}

Kişinin travma anında yaşadığı dissosiyasyonu geriye dönük olarak değerlendirmek amacı ile kullanılan bir öz bildirim ölçeğidir. Gerçeklik ve zamansal algıda bozulma, depersonalizasyon, konfüzyon ve beden dışı duygulanım boyutlarından oluşmaktadır. Türkçe geçerlik ve güvenilirlik çalışması Geyran ve arkadaşlarınca yapılmıştır ${ }^{15}$.

\section{DSM-5 Travma Sonrası Stres Bozukluğu Kontrol Listesi (TSSBKL)}

Her maddesi 0-4 arası puanlanan, son bir aydaki semptomları değerlendiren ve toplamda yirmi sorulu bir öz bildirim ölçeğidir. Her maddedeki puanların toplanması ile toplam belirti puanı hesaplanır ve kesme noktası 33 olarak bildirilmiştir. Türkçe geçerlik güvenilirlik çalışması Boysan ve arkadaşlarınca yapılmıştır ${ }^{16,17}$.

\section{İstatistiksel analiz}

Katılımcilardan elde edilen verilerin değerlendirilmesinde Statistical Package for Social Sciences (SPSS Inc., Chicago, IL) versiyon 20 program kullanıldı. Verilerin dağılımları Kolmogorov-Smirnov testi ile analiz edildi. Kategorik veriler sayı ve yüzde olarak, sayısal veriler ortalama ve standart sapma olarak gösterildi. Kategorik verilerin analizinde (demografik veriler gibi) ki kare testi kullanıldı. Katılımcılara uygulanan ölçekler arasında fark olup olmadığı Mann Whitney U testi ile ve ölçeklerin bir birleri ile ilişkisi Pearson korelasyon analizi ile gerçekleştirildi. Tüm analizlerde istatistik anlamlılık $\mathrm{p}<0,05$ olarak kabul edildi.

\section{BULGULAR}

Çalışmaya 360 kişi; 284 kişi depremi Elazığ il merkezinde yaşayan olgu grubu ve 76 kişi de farklı şehirlerde depremi hissetmeyen kişiler kontrol grubu olarak dahil edildi. Tüm katılımcılardan 187 kişi (\%41.5) erkek, 264 kişi (\%58.5) kadındı. Katılımcıların yaş ortalaması $30.9 \pm 9.9$ olarak hesapland1. Olgu grubu ve sağliklı kontrol grubunun demografik özellikleri Tablo 1'de sunulmuştur. Olgu grubunda enkaz altında kalan 3 kişi (\%1.1) olmuştur. Olgu grubunda yakınlarında can kaybı 11 kissi (\%3.87) bildirmiştir ve deprem sonrası kurtarma çalışmalarına 13 kişi (\%4.6) katıldığını ifade etmiştir. Deprem sonrası ciddi mal ve para kaybına 19 kişi (\%6.7) uğramıştır. Yirmi altı kişi (\%9.2) yeni eve yerleşmiş iken, 5 kişi (\%1.8) barınak/çadırda kaldığını belirtmiştir. Depremden sonra 22 kişi (\%7.7) farklı bir ile taşınmıştır. Tüm bunlara ek olarak 6 kişi (\%2.1) de psikiyatrik tedavi almaya başlamıstır.

Katılımcıların nicel değişkenlerinin dağglımı incelendiğinde; gruplar arasında Beck Anksiyete Ölçeği ve Beck Depresyon Ölçeği skorları arasında farklılık saptanmamıştır. Depremi yaşayan grupta; 143 kişinin (\%50.35) BDÖ skorları 0-9 arasında, 71 kişinin (\%25) kişinin 10-16 arasında, 42 kişinin (\%14.78) 17-29 arasında, 28 kişinin (\%9.85) ise 30-63 arasında idi. Kontrol grubunda ise 37 kişi (\%46.83) 09 arasında, 18 kişi (\%22.78) 10-16 arası, 12 kişi 
(\%15.18) 17-29 arası, 12 kişi (\%15.18) 30-63 arasında puan almıştır. Peritravmatik Dissosiyasyon Ölçeği ve DSM-5 Travma Sonrası Stres Bozukluğu Kontrol Listesi için depremi yaşayan olgu grubunda hesaplanan skorlar çok daha fazla idi (Tablo 2).

Depremi yaşayan olgu grubunun Pearson Korelasyon Analizi sonuçları Tablo 3'de verilmiştir. Depresyon ölçeği ile anksiyete ölçeği arasında yüksek düzey pozitif korelasyon saptanmıştır. Peritravmatik Dissosiyasyon Ölçeği ile anksiyete ve depresyon ölçeği pozitif yönde orta derecede ilişkili idi. Benzer şekilde DSM-5 Travma Sonrası Stres Bozukluğu Kontrol Listesi ile uygulanan diğer tüm ölçekler pozitif yönde orta şiddette ilişkili olarak saptand1 (Tablo 3).

Tablo 1. Katılımcıların demografik verilerinin ve depremle ilgili yaşantılarının dağılımı

\begin{tabular}{|c|c|c|c|}
\hline & $\begin{array}{c}\text { Depremi yaşayan } \\
\text { olgu grubu } \\
(\mathrm{n}=284)\end{array}$ & $\begin{array}{l}\text { Kontrol grubu } \\
\quad(n=76)\end{array}$ & $\mathbf{P}$ \\
\hline Yaş ortalamas1 (ort $\pm \mathrm{SS}$ ) & $32.09 \pm 9.93$ & $26.46 \pm 8.47$ & $<0.05 \mathrm{a}^{*}$ \\
\hline Cinsiyet (Kadın/erkek) & $174 / 110(\% 61.3 / 38.7)$ & $61 / 15(\% 80.3 / 19.7)$ & $0.002 b^{*}$ \\
\hline \multicolumn{4}{|l|}{ Medeni durum } \\
\hline Evli & $140(\% 49.3)$ & $12(\% 15.8)$ & \\
\hline Bekar & $136(\% 47.9)$ & $61(\% 80.3)$ & $0.790 \mathrm{~b}$ \\
\hline Eşinden ayrilmış & $8(\% 2.8)$ & $3(\% 3.9)$ & \\
\hline \multicolumn{4}{|l|}{ Eğitim düzeyi } \\
\hline İlkokul mezunu & $10(\% 3.5)$ & $1(\% 1.3)$ & \\
\hline Lise mezunu & $17(\% 6)$ & $5(\% 6.6)$ & \\
\hline Üniversite mezunu & $180(\% 63.4)$ & $54(\% 71.1)$ & $<0.05 b^{*}$ \\
\hline Üniversite öğrencisi & $77(\% 27.1)$ & $16(\% 21.1)$ & \\
\hline \multicolumn{4}{|l|}{ Mesleği } \\
\hline Memur & $122(\% 43.1)$ & $21(\% 27.6)$ & \\
\hline İşçi & $17(\% 6)$ & $4(\% 5.3)$ & \\
\hline Serbest meslek & $11(\% 3.9)$ & $3(\% 3.9)$ & $0.059 \mathrm{~b}$ \\
\hline Diğer iş kolları & $65(\% 23)$ & $17(\% 22.6)$ & \\
\hline İşsiz & $68(\% 24)$ & $31(\% 40.8)$ & \\
\hline \multicolumn{4}{|l|}{ Depremi nerede yaşadınız } \\
\hline 50 km'den yakın & $152(\% 53.5)$ & - & \\
\hline $50-100 \mathrm{~km}$ aras 1 & $46(\% 16.2)$ & - & - \\
\hline 100 km'den uzak & $86(\% 30.3)$ & - & \\
\hline \multicolumn{4}{|c|}{ Deprem sarsıntilarını hissettiniz mi? } \\
\hline Evet/hayır & $209 / 75(\% 73.6 / 26.4)$ & $0 / 100(\% 0 / 100)$ & - \\
\hline \multicolumn{4}{|c|}{ Deprem sirasinda neredeydiniz? } \\
\hline Binada & $234(\% 82.4)$ & - & \\
\hline Açık alanda & $19(\% 6.7)$ & - & \\
\hline Taşıtta & $5(\% 1.8)$ & - & - \\
\hline Diğer & $26(\% 9.2)$ & - & \\
\hline \multicolumn{4}{|c|}{ Evinizin hasar durumu nedir? } \\
\hline Sağlam & $190(\% 66.9)$ & - & \\
\hline Az hasarlı & $69(\% 24.3)$ & - & \\
\hline Orta hasarli & $8(\% 2.8)$ & - & \\
\hline Ağır hasarlı & $3(\% 1.1)$ & - & \\
\hline Deprem anında yıkıldı & $2(\% 0.7)$ & - & \\
\hline Deprem sonrası yıkıldı & $4(\% 1.4)$ & - & \\
\hline Hasar tespiti yapılmadı & $8(\% 2.8)$ & - & \\
\hline
\end{tabular}

Katılımcıların deprem öncesi psikiyatrik tedavi alımı yoktu.

Hesaplamalarda (a) Mann Whitney U testi ve (b) Ki kare testleri kullanılmıştır. Yaş satırında verilen değerler ortalamaさstandart sapma olarak sunulurken, diğer değerler n (\%) olarak sunulmuştur. 
Tablo 2. Katılımcıların nicel değişkenlerinin karşılaştırılması

\begin{tabular}{|l|c|c|c|}
\hline & $\begin{array}{c}\text { Depremi yaşayan olgu grubu } \\
(\mathbf{n = 2 8 4})\end{array}$ & $\begin{array}{c}\text { Kontrol grubu } \\
(\mathbf{n = 7 6 )}\end{array}$ & $\mathbf{P}$ \\
\hline BAÖ & $12.09 \pm 11.19$ & $12.03 \pm 9.47$ & 0.569 \\
\hline BDÖ & $12.25 \pm 10.65$ & $11.55 \pm 10.12$ & 0.643 \\
\hline PTDÖ & $8.46 \pm 8.69$ & $3.92 \pm 5.73$ & $<0.05^{*}$ \\
\hline TSSBKL & $23.78 \pm 19.32$ & $19.59 \pm 19.82$ & $0.049^{*}$ \\
\hline
\end{tabular}

Tabloda verilen kısaltmalar: BAÖ: Beck Anksiyete Ölçeği; BDÖ: Beck Depresyon Ölçeği; PTDÖ: Peritravmatik Dissosiyasyon Ölçeği; TSSBKL: DSM-5 Travma Sonrası Stres Bozukluğu Kontrol Listesi.

Tabloda verilen değerler ortalama \pm standart sapma olarak sunulmuştur. Hesaplamalarda Mann Whitney U testi kullanılmıştır. *p $<0.05$.

Tablo 3. Depremi yaşayan olgu grubunun Pearson korelasyon analizi sonuçları

\begin{tabular}{|l|l|l|l|}
\hline & BAÖ & BDÖ & PTDÖ \\
\hline BDÖ & $0.607^{*}$ & - & $0.369^{*}$ \\
\hline PTDÖ & $0.501^{*}$ & $0.369^{*}$ & - \\
\hline TSSKL & $0.594^{*}$ & $0.558^{*}$ & $0.500^{*}$ \\
\hline
\end{tabular}

Tabloda verilen kısaltmalar: BAÖ: Beck Anksiyete Ölçeği; BDÖ: Beck Depresyon Ölçeğí PTDÖ: Peritravmatik Dissosiyasyon Ölçeği; TSSBKL: DSM-5 Travma Sonrası Stres Bozukluğu Kontrol Listesi.

Tabloda verilen değerler " $r$ ” değerleridir. Hesaplamalarda Pearson Korelasyon analizi kullanılmıştır; *p<0.05.

\section{TARTIŞMA}

Çalışmamızda 24.01.2020 tarihinde merkez üssü Elazı $\breve{g}$ Sivrice ilçesi olan, depremin ortaya çıkardığ1 psikiyatrik semptomlar ve hastalıkları değerlendirilmiştir. Elde ettiğimiz sonuçlarda; grupların anksiyete ve depresyon skorları arasında farklılık saptanmamıştır. Fakat depremi yaşayan grubun hem peritravmatik dissosiyasyon ölçeği skorları hem de travma sonrası kontrol listesi skorlar1 kontrol grubundan yüksek hesaplanmıştır.

Elazı̆̆ Sivrice ilçesinde yaşanan depremde; merkez Elazığ'da 8519, Malatya'da 3795 yapı yıkılmış veya ağır hasar görmüştür. Beraberinde bin beş yüzün üzerinde insan yaralanmış ve resmi rakamlara göre 44 kişi vefat etmiştir ${ }^{18}$. Bu ve benzeri can ve mal kaybına yol açan büyük afetlerden sonra yaşanan psikiyatrik semptomlar ve hastalıklar üzerine literatürde çalışmalar yapılmıştır ${ }^{7-10}$. İran'da 2017 yılında yaşanan ve 620 kişinin vefat ettiği depremden on gün sonra bir çalışma yapılmıştır. $\mathrm{Bu}$ çalışmanın sonuçlarında deprem mağdurlarının; \%70 oran ile orta derecede kayg1, \%60.5 oran ile yoğun stres, $\% 41.5$ oran ile depresif semptomlar yaşadıkları ve \%20.61 oran ile uyku kalitelerinin bozulduğu tespit edilmiştir $^{19}$. Başka bir çalışmada Ekvator 2016 depreminden 9 ay sonra yapılmıştır. Bu çalışmada 1319 yaş grubu ergenler değerlendirilmiştir. Sonucunda travma sonrası stres bozukluğu, depresif bozukluk, anksiyete bozukluğu ve intihar düşüncesinde artış saptanmıştır ${ }^{20} .976$ y1lında Çin Tangshan eyaletinde yaşanan ve 240.000 kişinin ölümü ile sonuçlanan depremden 37 yıl sonra bir çalışma yapılmıştır. Bu çalışmada deprem sonrası aynı yerde yaşamaya devam eden kişiler depresyon skorları açısından incelenmiştir. Sadece depremi yaşayan kadınların depresyon skorlarının yükseldiği, erkeklerde böyle bir yükselme olmadığ1 tespit edilmiştir ${ }^{21}$. Bizim sonuçlarımızda depremi yaşayan katılımcılar depremden 2,5 ay sonra değerlendirilmiştir. Zaman kısa olmasına rağmen depremi yaşayan katılımcıların depresyon ölçeği skorları sağlıklı kontrollere göre yüksek bulunmuştur fakat istatistiksel olarak farklilık tespit edilmemiştir.

Travma sonrası stres bozukluğu (PTSB); stres etmeni ve/veya travma ile ilişkili bir psikiyatrik hastalık olup, travmatik olaydan haftalar veya aylar sonra ortaya çıııp yılarca sürebilmektedir. PTSB; deprem gibi doğal felaketlerden sonra en sık görülen psikiyatrik hastalıklardan biridir. 3 Yapılan bir meta-analiz çalışmasında; MEDLINE, PubMed, EMBASE ve PsycINFO gibi kaynak taramasinda deprem sonras1 PTSB'nin en fazla bildirilen psikiyatrik durum olduğu tespit edilmiştir ${ }^{22}$. 2011 yllında Japonya'da meydana gelen ve 15.828 kişinin hayatını kaybettiği depremden iki buçuk yıl sonra kişilerin PTSB riskini belirleyebilmek adına bir çalışma yapılmıştır. Çalışmanın sonuçlarında katılımcıların \%11.4 oran ile PTSB semptomları yaşadığı saptanmıştır. Ek olarak afet öncesi sosyal ve toplumsal uyumu iyi olan bireylerin daha az PTSB semptomları yaşadığ gösterilmiştir ${ }^{23} .2015$ yılında Nepal'de 8.000 kişinin ölümü ile sonuçlanan depremden on ay sonra bir çalışma yapılmıştır. PTSB semptomu olmayan hayatta 
kalanların aktif olarak başa çıkma tutumlarının yüksek olduğu, PTSB semptomu olanların ise pasif başa çıkma, dini başa çıkma ve madde kullanımı skorlarının yüksek olduğu saptanmıştır ${ }^{24}$. Benzer şekilde bizim sonuçlarımızda da depremi yaşayan olgu grubunun travma sonrasi kontrol listesi skorlarının kontrol grubundan literatür ile uyumlu olarak beklenileceği üzere yüksek olduğu tespit edilmiștir.

Literatürde deprem ya da başka doğal afetler sonrası yaşanan dissosiyasyon ile ilgili çalışmalar yapılmıştır 25-28. Haiti 2010 yilı yaşanan deprem sonrası hayatta kalan kişiler ile yapılan bir çalışmada katılımcılara PTSB semptom kontrol listesi ve peritravmatik disosiyasyon ölçeği uygulanmıştır. Bu çalışmada uygulanan peritravmatik dissosiyasyon ölçeği kesme puanı 22 iken katılımciların $24.75 \pm 8.88$ puan elde ettiği görülmüştür ${ }^{26}$. Yapılan başka bir çalışmada dissosiyasyon travma sonrasi stres belirtileri ile pozitif ilişkili olarak saptanmıștır ${ }^{27}$. Ülkemizde Van depremi sonrası yapılan bir çalışmada benzer şekilde travma sonras1 stres belirtileri ve dissosiyatif semptomlar ilişkili olarak saptanmıştır ${ }^{28}$. Bizim sonuçlarımızda literatür ile benzer nitelikte olmuştur. Depremi yaşayan olgu grubunun dissosiyasyon skorları hem sağlıklı kontrollerden yüksek hem de travma sonrası kontrol listesi ile dissosiyasyon skorları pozitif yönde orta düzeyde ilişkili olarak saptanmıştır.

Sonuçlarımız bazı kısıtllıklar göz önüne alınarak değerlendirilmelidir. Bu kısıtlılıklardan ilki; örneklem sayımızın görece yetersiz sayıda oluşu, öz bildirim ölçekleri ile ve yaşanan depremden kısa süre sonra kişilerin değerlendirilmesi kısıtlılıklar arasında sayılabilir. Bu durum elde ettiğimiz sonuçların genellemesi ve yorumlanmasını sınırlamaktadır. Elde etiğimiz bulguların önem kazanabilmesi için daha büyük örneklem gruplarında daha ileri araştırmalar yapilmasına gerek vardır.

Elde ettiğimiz sonuçlara dayanarak; deprem gibi can ve mal kaybına yol açan felaketler sonrası hayatta kalan kişilerin psikiyatrik şikayetlerinin ve semptomlarının erken dönemde tanımlanmasının ne kadar önemli olduğu söylenebilir. Erken dönemde ortaya konulan psikiyatrik semptomlar aracıllŏg ile erken dönemde psikiyatrik hastalıklar için tanı konulup hızlica müdahale edilebilir. Ek olarak etkilenen insanlara barınma ve iş olanakları sağlanmasına yardımcı olunup, psikolojik ve sosyal destek grupları oluşturulabilir. Alınacak bu tedbirler aracılığı ile psikiyatrik semptomlar ve hastalıların iyileşme sürecine girmesi ve iyileşmenin hızlanması da dolaylı olarak sağlanabilir.

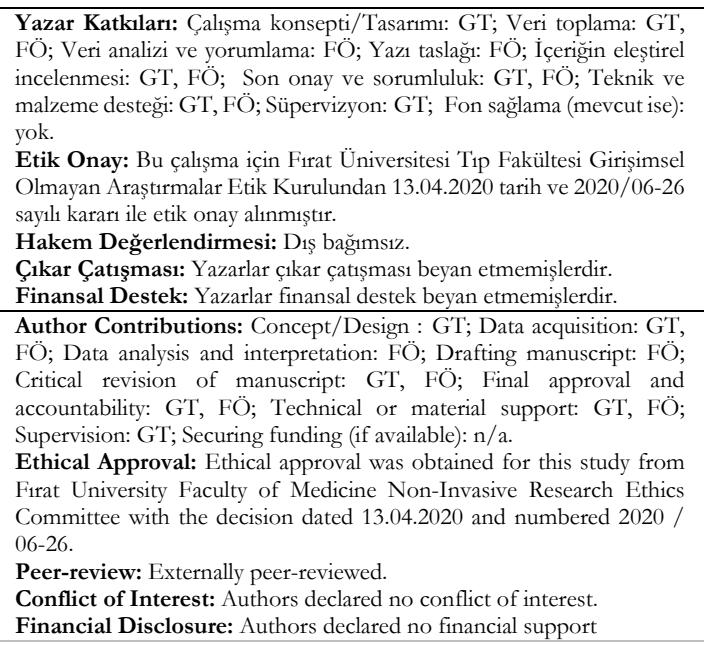

\section{KAYNAKLAR}

1. 1. United States Geological Survey. United States Geological Survey's, Earthquake facts. Available from https://earthquake.usgs.gov/ learn/facts.php. Accessed 2015 Dec 16.

2. Wu Z, Xu J, He L. Psychological consequences and associated risk factors among adult survivors of the 2008 Wenchuan earthquake. BMC Psychiatry. 2014;14:1-11.

3. Farooqui M, Quadri SA, Suriya SS, Khan MA, Ovais M, Sohail Z, et al. Posttraumatic stress disorder: a serious post-earthquake complication. Trends Psychiatry Psychother. 2017;39:135-43.

4. Naeem F, Ayub M, Masood K, Gul H, Khalid M, Farrukh A, et al. Prevalence and psychosocial risk factors of PTSD: 18 months after Kashmir earthquake in Pakistan. J Affect Disord. 2011;130:268-74.

5. Long J, Huang X, Liao Y, Hu X, Hu J, Lui S, et al. Prediction of post-earthquake depressive and anxiety symptoms: a longitudinal resting-state fMRI study. Sci Rep. 2014;4:6423.

6. Blanc J, Bui E, Mouchenik Y, Derivois D, Birmes P. Prevalence of post-traumatic stress disorder and depression in two groups of children one year after the January 2010 earthquake in Haiti. J Affect Disord. 2014;172:121-6.

7. Cankardaş S, Sofuoğlu Z. Deprem ya da yangın deneyimlemiş kişilerde travma sonrası stres bozukluğu belirtileri ve belittilerin yordayıcıları. Turk Psikiyatri Derg. 2019;30:151-6.

8. Roberts YH, Mitchell MJ, Witman M, Taffaro C. Mental health symptoms in youth affected by Hurricane Katrina. Prof Psychol Res Pr. 2010;41:108. 
9. Norenzayan A, Lee A. It was meant to happen: explaining cultural variations in fate attributions. J Pers Soc Psychol. 2010;98:702-20.

10. World Medical Association. World Medical Association Declaration of Helsinki: ethical principles for medical research involving human subjects. JAMA. 2013;310:2191-4.

11. Beck AT, Epstein N, Brown G, Steer RA. An inventory for measuring clinical anxiety: psychometric properties. J Consul Clin Psychol.1988;56:893-7.

12. Ulusoy M, Şahin N, Erkmen H. Turkish version of The Beck Anxiety Inventory: psychometric Properties. J Cogn Psychother. 1998;12:28-35.

13. Beck AT, Ward CH, Mendelson M, Mock J, Erbaugh J. An inventory for measuring depression. Arch Gen Psychiatry.1961;4:561-71.

14. Hisli N. Beck Depresyon Envanterinin üniversite öğrencileri için geçerliliği, güvenirliği. Psikoloji Dergisi. 1989;7:3-13.

15. Geyran P, Kocabaşoğlu N, Özdemir-Çorapçıŏlu A. Peritravmatik Dissosiyasyon Ölçeği (PDEQ) Türkçe versiyonunun geçerlilik ve güvenilirliği. Yeni Symposium.2005;43:79-84.

16. Weathers FW, Litz BT, Keane TM, Palmieri PA, Marx BP, Schnurr PP. The PTSD checklist for DSM-5 (PCL-5). Washington DC, National Center for PTSD, 2013.

17. Boysan M, Özdemir PG, Özdemir O, Selvi Y, Yılmaz E, Kaya N. Psychometric properties of the Turkish version of the PTSD checklist for diagnostic and statistical manual of mental disorders, fifth edition (PCL-5). Psychiatry Clin Psychopharmacol. 2017;27:306-16.

18. AFAD. Elazı̆̆ ve Malatya'da deprem sonrası müdahale ve iyileştirme çalışmaları devam ediyor. Available from https://elazig.afad.gov.tr/elazig-vemalatyada-deprem-sonrasi-mudahale-ve-iyilestirmecalismalari-devam-ediyor adresinden ulaşılmıştır. Accessed 11.02.2020

19. Bavafa A, Khazaie H, Khaledi-Paveh B, Rezaie L. The relationship of severity of symptoms of depression, anxiety, and stress with sleep quality in earthquake survivors in Kermanshah. J Inj Violence Res. 2019;11:225.

20. Gerstner RM, Lara-Lara F, Vasconez E, Viscor G, Jarrin JD, Ortis-Prda E. Earthquake-related stressors associated with suicidality, depression, anxiety and post-traumatic stress in adolescents from Muisne after the earthquake 2016 in Ecuador. BMC Psychiatry. 2020;20:347.

21. Gao X, Leng Y, Guo Y, Yang J, Cui Q, Geng B, et al. Association between earthquake experience and depression 37 years after the Tangshan earthquake: a cross-sectional study. BMJ Open. 2019;9:e026110.

22. Cheng Y, Wang F, Wen J, Shi Y. Risk factors of posttraumatic stress disorder (PTSD) after Wenchuan earthquake: a case control study. PLoS One. 2014;9:e96644.

23. Hikichi H, Aida J, Tsuboya T, Kondo K, Kawachi I. Can community social cohesion prevent posttraumatic stress disorder in the aftermath of a disaster? A natural experiment from the 2011 Tohoku earthquake and tsunami. Am J Epidemiol. 2016;183:902-10.

24. Baral IA, Bhagawati KC. Post traumatic stress disorder and coping strategies among adult survivors of earthquake, Nepal. BMC Psychiatry. 2019;19:1-8.

25. Canan F, North CS. Dissociation and disasters: A systematic review. World J Psychiatry. 2019;9:83.

26. Blanc J, Rahill GJ, Laconi S, Mouchenik Y. Religious Beliefs, PTSD, Depression and Resilience in Survivors of the 2010 Haiti Earthquake. J Affect Disord. 2016;190:697-703

27. Kannis-Dymand L, Carter JD, Lane BR, Innes P. The relationship of peritraumatic distress and dissociation with beliefs about memory following natural disasters. Australian Psychol. 2019;54:311-21.

28. Özdemir O, Boysan M, Özdemir PG, Yilmaz E. Relations between post-traumatic stress disorder, dissociation and attention-deficit/hyperactivity disorder among earthquake survivors. Nöro Psikiyatri Ars. 2015;52:252. 